\title{
13 INTERVENTION PROGRAM FOR PERPETRATORS OF INTIMATE PARTNER VIOLENCE IN MEXICO: PRELIMINARY RESULTS AND LESSON LEARNED
}

doi:10.1136/injuryprev-2012-040590q.13

González-Focke Mariana, Valdez-Santiago Rosario, Rodríguez-Hernández Jorge Martín. Health System Research Centre of the National Institute of Public Health (NIPH), Morelos, México

Background In 2007, Mexico's Congress passed the General Law of Women's Access to Lives Free from Violence. One of the obligations set forth by the law is that all governmental sectors, in particular the health sector, need to collaborate to carry out programs aimed at 're-educating' victims and perpetrators of intimate partner violence so that cycles of abuse and re-victimisation are broken. In this context arises the Intervention program.

Aims Characterise the participants, present difficulties in implementation, impacts and lessons learned during 2010.

Methods We used qualitative and quantitative indicators, monitoring and program evaluation applied in 8 states.

Results In 2010, 1257 men participated in the program with an average age of 35.3 years; were linked via recommendation of friends $(46.3 \%)$ and direct invitation to your partner (12.6\%). The first difficulty was to break the resistance to participation, then an appropriate proposal to raise the working conditions of participants. This implied 'out' of the health centers to collaborate with other community social services. Upon joining, participants expressed that they did to improve family relationships (47\%) and because they wanted to leave from violence (12\%). Evaluation data show that the program generated important changes in 
participants. Men identified forms of violence that prior they did not recognise as such and they were able to develop strategies to detain themselves (such as leaving a situation before it became violent). One challenge is to improve retention and adherence of the participants, as only $5 \%$ attended more than $75 \%$ of the sessions of the program.

Significance Demonstrated the importance and feasibility of carrying out innovative work with perpetrators of IPV in Mexico.

Contains a model of care that is a relevant public policy proposal that addresses a central theme in the context of Mexican society. 